\title{
PReS-FINAL-2035: Fatty acid profiling: potential new biomarkers in JIA
}

\author{
C Boros $^{1 *}$, WT CHAM ${ }^{1}$, J Fletcher ${ }^{2}$, E Ranieri ${ }^{2}$ \\ From 20th Pediatric Rheumatology European Society (PReS) Congress \\ Ljubljana, Slovenia. 25-29 September 2013
}

\section{Introduction}

The prostanoids are a family of biologically active lipids derived from the 20-carbon essential fatty acids (LCPUFA) which are involved in all aspects of the immune response including the resolution of inflammation. $\omega 3$-fatty acids, EPA DPA and DHA are anti-inflammatory, whilst the 06 fatty acid, Arachidonic acid (AA) and its metabolites: 13 (S)-HETE, TXB2, PGF2 $\alpha$ and 6-k-PGF1 $\alpha$ are pro-inflammatory. Liquid Chromatography Tandem Mass Spectrometry (LC-MSMS) allows analyses of multiple prostanoids with high accuracy using $3 \mathrm{~mm}$ blood spots. This method has never been used in JIA and may find biomarkers which can help predict disease activity and treatment response.

\section{Objectives}

To measure prostanoid profiles in patients with JIA using LC-MSMS.

\section{Methods}

254 samples from 114 JIA patients and 6 healthy controls (HC) were collected onto specially prepared filter papers and analysed using LC-MSMS.

\section{Results}

The JIA M:F ratio was 1:1.4, the average age at study entry $(9.4 \pm 5.0 \mathrm{y})$, average disease duration (56.1 \pm
$46.1 \mathrm{~m})$, with $25 \%$ JIA receiving treatment with NSAID, 11\% with Methotrexate (MTX), and 10\% with Biologics. 13(S)HODE and DHA levels were significantly different between JIA patient groups $(\mathrm{p}=0.05$ for both; 13(S)HODE oligo vs poly $\mathrm{p}=0.02$; DHA SoJIA vs RF+ Poly $p=0.007)$. There was a positive correlation between JADAS and PGB2 $(p=0.046)$. There were lower levels of pro-inflammatory prostanoids in JIA (Table 1).

\section{Conclusion}

In our JIA cohort, we found that PGB2 is correlated with disease activity and that levels of pro-inflammatory prostanoids are reduced, particularly in polyarthritis. This may reflect the degree to which the pro-resolving prostanoids are activated in patients with relatively long average disease duration. It is also possible that measurement of a combination of prostanoids will help us predict changes in disease activity and treatment response over time more accurately. Longitudinal analysis the relationship between disease activity and prostanoid profiles is underway.

\section{Disclosure of interest}

None declared.

Table 1

\begin{tabular}{|c|c|c|c|c|c|c|c|}
\hline Prostanoid/JIA subtype & Oligo & Extended Oligo & Poly & RF+ Poly & JPSA & ERA & SoJIA \\
\hline HODE & & & $p=0.001$ & & $p=0.002$ & $p=0.01$ & \\
\hline DPA & & & $p=0.02$ & & $p=0.017$ & $p=0.01$ & \\
\hline PGF2a & $p=0.001$ & $p=0.03$ & $p=0.007$ & & & & $p=0.04$ \\
\hline TBX2 & $p=0.009$ & $p=0.004$ & $p<0.001$ & $p=0.007$ & $p=0.04$ & & \\
\hline
\end{tabular}

'Uni Dept Paedaitrics, Womens and Childrens Hospital, Australia

Full list of author information is available at the end of the article 


\title{
Authors' details
}

'Uni Dept Paedaitrics, Womens and Childrens Hospital, Australia.

${ }^{2}$ Biochemical genetics, IMVS pathology, Adelaide, Australia.

Published: 5 December 2013

\author{
doi:10.1186/1546-0096-11-S2-P48 \\ Cite this article as: Boros et al:: PReS-FINAL-2035: Fatty acid profiling \\ potential new biomarkers in JIA. Pediatric Rheumatology 2013
}

11(Suppl 2):P48.

Submit your next manuscript to BioMed Central and take full advantage of:

- Convenient online submission

- Thorough peer review

- No space constraints or color figure charges

- Immediate publication on acceptance

- Inclusion in PubMed, CAS, Scopus and Google Scholar

- Research which is freely available for redistribution 